Original article

\title{
Tobacco use among health care workers of tertiary care center of Faridabad, Haryana, India
}

\author{
Nidhi Prasad ${ }^{\mathrm{a}}$, Mitasha Singh ${ }^{\mathrm{b}, *}$, Ravi Kiran Pal ${ }^{\mathrm{b}}$, Jefin Joseph $^{\mathrm{b}}$ \\ ${ }^{a}$ Community Medicine, Indira Gandhi Institute of Medical Sciences, Patna, Bihar, India \\ ${ }^{\mathrm{b}}$ Community Medicine, ESIC Medical College and Hospital, Faridabad, Haryana, India
}

\section{A R T I C L E I N F O}

\section{Keywords:}

Tobacco consumption

Housekeeping staff

Nursing orderlies

Qualitative study

\begin{abstract}
A B S T R A C T
Background: Associated health risks and increasing mortality with tobacco consumption has been increasing. If people involved in health care of the community practice the same it may further increase the magnitude of problem.

Objectives: To assess the prevalence and reasons of tobacco consumption among health care workers (housekeeping staff and nursing orderlies) of a tertiary care center in Haryana, India.

Methods: It was a fully mixed concurrent dominant status design with dominant quantitative part where cross sectional design was used. The qualitative component used phenomenology. All the housekeeping staff and nursing orderlies working (306 total) at a tertiary care center, Faridabad were recruited in the study. In depth interview was conducted on twenty workers (12 housekeeping staff and 8 nursing).

Results: Overall prevalence of tobacco consumption was 43.4\%. Among tobacco users, smokeless tobacco was used by more than half of housekeeping staff (53.2\%). Nursing orderly preferred smoked form i.e. cigarette (41\%). Participants discussed social and cultural conditions in Haryana under which smoking hookah are practiced and maintained. Smoking as a means of socializing and relaxation were consistently discussed as the main reasons for continued use in everyday lives. Working condition was a compelling factor for housekeeping staff leading to its continuous use to carry on the current job.

Conclusion: Tobacco consumption among health workers is higher as compared to general population. Appreciating their diverse representations their attitudes towards health and anti-tobacco measures; would increase acceptance of policies and probability that can lead to positive outcomes.
\end{abstract}

\section{Introduction}

Worldwide, Tobacco consumption has become a major public health and social problem with World Health Organization (WHO) estimates of annual 4.9 million deaths due to tobacco consumption. ${ }^{1}$ In India, the deaths attributed to tobacco use, are expected to rise from $1.4 \%$ of all deaths in 1990 to $13.3 \%$ by $2020 .^{2}$ The Global Youth Tobacco Study (GYTS) has reported that both smoking and smokeless tobacco consumption are prevalent in developing countries. ${ }^{3}$ as per Global Adult Tobacco Survey 2016-17 the prevalence of tobacco use in Haryana was found to be $23.6 \%{ }^{4}$

Several studies have shown a high prevalence of smokers among health workers and providers, ${ }^{5-7}$ who do not always set a good example for their patients. ${ }^{8}$ This is despite the assumptions of an occupational class being aware of risk factors of diseases. Most of the health care setting staff is in their economically productive age group. Their lifestyle and behavior influences the patients and their attendants. They are bound to act ideally in many situations. The diseases caused by tobacco use are not only burdening the health system but also resulting in higher loss of economy. Although the damages of tobacco are well known still there are myths related to its use. With a hypothesis that healthcare workers have better awareness about tobacco use and its harmful effects we tried to explore the behavior in two groups of workers about tobacco use.

\section{Objective}

The following study was planned to estimate tobacco use prevalence among a sample of hospital work force (housekeeping staff and nursing orderlies) and to explore the reasons of tobacco use so that it can be

\footnotetext{
* Corresponding author.

E-mail addresses: drnidhi2001@gmail.com (N. Prasad), mitasha.17@gmail.com (M. Singh), palrk2002@gmail.com (R.K. Pal), jefwin56@rediffmail.com (J. Joseph).
} 
specifically targeted.

\section{Methodology}

\subsection{Study design}

It was a fully mixed concurrent dominant status design with dominant quantitative part where Cross sectional design was used. The qualitative component used phenomenology.

\subsection{Study area and duration}

The study was conducted in the campus of a tertiary care center of Haryana from June 2018 through December 2018.

\subsection{Study population}

The housekeeping staff and nursing orderlies of tertiary care center of Haryana were included in the study.

\subsection{Sample size and sampling}

Universal sampling was used.

\subsubsection{Inclusion criteria}

1. All the operational level housekeeping staff who are unskilled workers.

2. All semi skilled nursing orderly (who assists in personal hygiene, feeding and attending of patients) working in the hospital.

\subsubsection{Exclusion criteria}

1. Those who did not provide consent to participate in study were excluded.

2. The managerial and supervisory staff was excluded.

\subsection{Study tool}

For quantitative component semi-structured pre tested self administered questionnaire was used. Whereas informal conversational interview with 20 workers which included 12 housekeeping staff and 8 nursing orderly.

\subsection{Data collection}

Data was collected by face to face Interview method using semistructured questionnaire having questions pertaining to socio demographic details and tobacco use. Interviews were conducted by the principal investigator and medical social worker of the department of Community Medicine after prior training. Informed consent was obtained after explaining the purpose of study. Anonymity was maintained by giving alphanumeric codes to study population instead of names. Upon receipt of the permission from the supervisors of both the groups of study population, we contacted the workers and encouraged their co-workers to participate in the study. The study purpose was explained to all eligible participants. The interviews were conducted on weekdays and during lunch break. Maximum two interviews were conducted in a day. While one of the investigators interviewed the study participant the second investigator took notes in the language spoken by the participant.

\subsection{Operational definition}

Current user: Using tobacco regularly within 1 month prior to examination;
Nontobacco users: Never used tobacco or occasionally used tobacco; Ex -tobacco user:

Stopped more than 1 month prior to the interview.

\subsection{Data and statistical analysis}

The quantitative data was entered in Microsoft excel sheet and analyzed using Epi info version 7. The categorical variables are presented as number and proportions. Qualitative data was subjected to verbatim transcription by the two interviewers. The transcripts were reread and coded by third investigator. The codes were categorized into sub codes by the three investigators. The themes were further developed.

\subsection{Ethical justification}

Investigator and supervisor are aware of the ethics in biomedical research policy of ICMR (2006) and declaration of Helsinki revised in 2002. The ethical clearance was obtained from the institute ethical committee for biomedical research (letter no. 134/A/11/16/Academic/ MC/2016/106). Informed consent of all participants was obtained before gathering any information.

\section{Results}

\subsection{Participants' characteristics}

Majority (54.9\%) of study population was young adults (18-29 years) and males (82.7\%). The education status of housekeeping staff in majority ranged from can read and write to high school (78\%), while half of nursing orderly (50.9\%) were graduate. Majority of the study population were married $(80.4 \%)$ (Table 1$)$.

\subsection{Tobacco use}

Majority of tobacco users belonged to 18-29 (55.6\%) and none of the housekeeping staff using tobacco was $>50$ years old. Housekeeping staff using tobacco had in majority attained education below higher secondary and $10.6 \%$ were illiterate. Majority of NOs had completed graduation (64.1\%). Majority of tobacco users were married $(81.2 \%)$.

Table 1

Demographic characteristics of Hospital Staff (housekeeping and nursing orderly).

\begin{tabular}{llll}
\hline Study population & Housekeeping (196) & Nursing Orderly (110) & Total (306) \\
\hline Age in years & & & \\
$18-29$ & $98(50)$ & $70(64)$ & $168(54.9)$ \\
$30-39$ & $66(33.6)$ & $33(30)$ & $99(32.4)$ \\
$40-49$ & $32(16.4)$ & $4(3)$ & $36(11.8)$ \\
$>50$ & 0 & $3(3)$ & $3(0.09)$ \\
Gender & & & \\
Male & $156(79.6)$ & $97(88.2)$ & $253(82.7)$ \\
Female & $40(20.4)$ & $13(11.8)$ & $53(17.3)$ \\
Current Tobacco Consumption & & $133(43.5)$ \\
Yes & $94(47.9)$ & $39(35.5)$ & $173(56.5)$ \\
No & $102(52.1)$ & $71(64.5)$ & $246(80.4)$ \\
Marital Status & & & $60(19.6)$ \\
Married & $182(92.9)$ & $64(58.2)$ & \\
Unmarried/Widow & $14(7.1)$ & $46(41.8)$ & $22(7.2)$ \\
Education status & & & $31(10.1)$ \\
Illiterate & $22(11)$ & 0 & $33(10.8)$ \\
Can read and write & $31(16)$ & 0 & $52(16.9)$ \\
Primary & $33(12)$ & 0 & $40(13.1)$ \\
Middle & $52(28)$ & 0 & $52(16.9)$ \\
High School & $40(22)$ & 0 & $66(21.6)$ \\
Intermediate & $8(5)$ & $44(40.0)$ & $10(3.3)$ \\
Graduate & $10(6)$ & $56(50.9)$ & \\
Postgraduate & 0 & $10(9.1)$ & \\
\hline
\end{tabular}


Table 2

Demographic Characteristics of current tobacco users.

\begin{tabular}{|c|c|c|c|}
\hline & Housekeeping N(\%) & Nursing Orderly N (\%) & Total N (\%) \\
\hline Tobacco users & $94(70.7)$ & $39(29.3)$ & $133(100)$ \\
\hline \multicolumn{4}{|l|}{ Age in years } \\
\hline $18-29$ & $51(54.3)$ & $23(58.9)$ & $74(55.6)$ \\
\hline $30-39$ & $25(26.6)$ & $13(33.3)$ & $38(28.6)$ \\
\hline $40-49$ & $18(19.1)$ & 0 & $18(13.5)$ \\
\hline$>50$ & 0 & $3(0.08)$ & $3(2.3)$ \\
\hline \multicolumn{4}{|l|}{ Gender } \\
\hline Male & $89(94.7)$ & $38(97.4)$ & $127(95.5)$ \\
\hline Female & $8(5.3)$ & $1(3.6)$ & $9(4.5)$ \\
\hline \multicolumn{4}{|l|}{ Education } \\
\hline Illiterate & $10(10.6)$ & 0 & $10(7.5)$ \\
\hline Literate & $21(22.3)$ & 0 & $21(15.8)$ \\
\hline Primary & $13(13.8)$ & 0 & $13(9.8)$ \\
\hline Middle & $13(13.8)$ & 0 & $13(9.8)$ \\
\hline Higher Secondary & $18(19.1)$ & 0 & $18(13.5)$ \\
\hline Intermediate & $3(3.2)$ & $11(28.9)$ & $14(10.5)$ \\
\hline Graduate & $5(5.3)$ & $25(64.1)$ & $30(22.6)$ \\
\hline Post Graduate & 0 & $2(5.1)$ & $2(1.5)$ \\
\hline \multicolumn{4}{|l|}{ Marital status } \\
\hline Married & $73(77.7)$ & 35 (89.7) & $108(81.2)$ \\
\hline Unmarried/Widow & $21(22.3)$ & $4(10.3)$ & $25(18.8)$ \\
\hline
\end{tabular}

Overall prevalence of tobacco use was 43.4\%; prevalence of $30.7 \%$ among housekeeping and $12.7 \%$ among nursing orderlies (Table 2).

Smokeless form of tobacco was used by majority of housekeeping staff in form of gutkha, pan masala and other chewable (53.2\%). Nursing orderly preferred smoked form i.e. cigarette (41\%). Bidi was used by $17 \%$ of housekeeping staff. Hookah was used by $25.6 \%$ of NOs and $19.1 \%$ of housekeeping staff (Fig. 1).

\subsection{Themes for reason for tobacco intake (Table 3)}

\subsubsection{Culture/custom/mandatory}

The participants of the study hailed from the state of Haryana where Hookah is passed on from one generation to other hence it is a tradition. Khaini or pan is culturally acceptable among migrants from other states like Bihar. Hookah using population labeled it as harmless; believing that the smoke was filtered through water and then inhaled.

A nursing orderly quoted that "Smoking hookah is a tradition in our family. It was passed on from our forefathers to me. I use hookah at home and bidi or chew khaini at work."

\subsubsection{Working condition compels to use tobacco}

Participants involved in housekeeping usually worked as sweepers,
Table 3

Summary of main themes and sub themes emerged during interview.

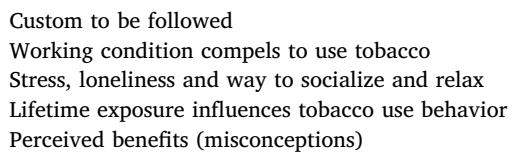

laundry cleaners, dish cleaners. Similarly nursing orderlies in hospital were involved in patient care that included bedside cleaning of urine and stool, changing of soiled linen of patients, transfer of instruments etc. Many of these participants quoted that the nature of their job compelled them to stay in places with unpleasant smell. This also led them to think that the infected air from hospital and toilet can be prevented from entering their mouth by keeping smokeless form of tobacco in their mouth during work. Also non availability of masks for them makes them use measures which can prevent anything to enter their mouth.

A housekeeping staff said "...the nature of job is dirty hence I take it..." The staff who used to clean the toilets quoted that "...Khaini obstructs the outside bad air from entering the body through mouth." A laundry worker said that "The sweet smell of khaini obstructs the bad smell of hospital ..."

\subsection{Stress, loneliness and way to socialize and relax}

Study participants who were involved in hospital duties at night shift used to chew tobacco to stay awake and pass their time with other colleagues on duty. A few described stress in family, tension with partner and loneliness as a trigger to use tobacco in any form. Most participants described it as a help when they were feeling low. Others found a relief in it when they were tensed after a quarrel at home.

Many housekeeping staff described that due to lot of free time available after cleaning and sweeping they wanted to join their peers for company as a means to relax and gossip, that would easily kill the time. Sitting in a group motivated (exposed) them to try all (different) forms of tobacco and this eventually became a pleasure and their habit.

A night shift worker quoted that "During night duties ... I take it (gutkha) to stay awake and pass my time." Another nursing orderly said "At home ... there is lot of stress ... Gutkha relieves that for some time." A young housekeeping staff said "... the colleagues give it to me when I sit with them. I do not buy it myself ... It is taken for pleasure and also it is a time pass"

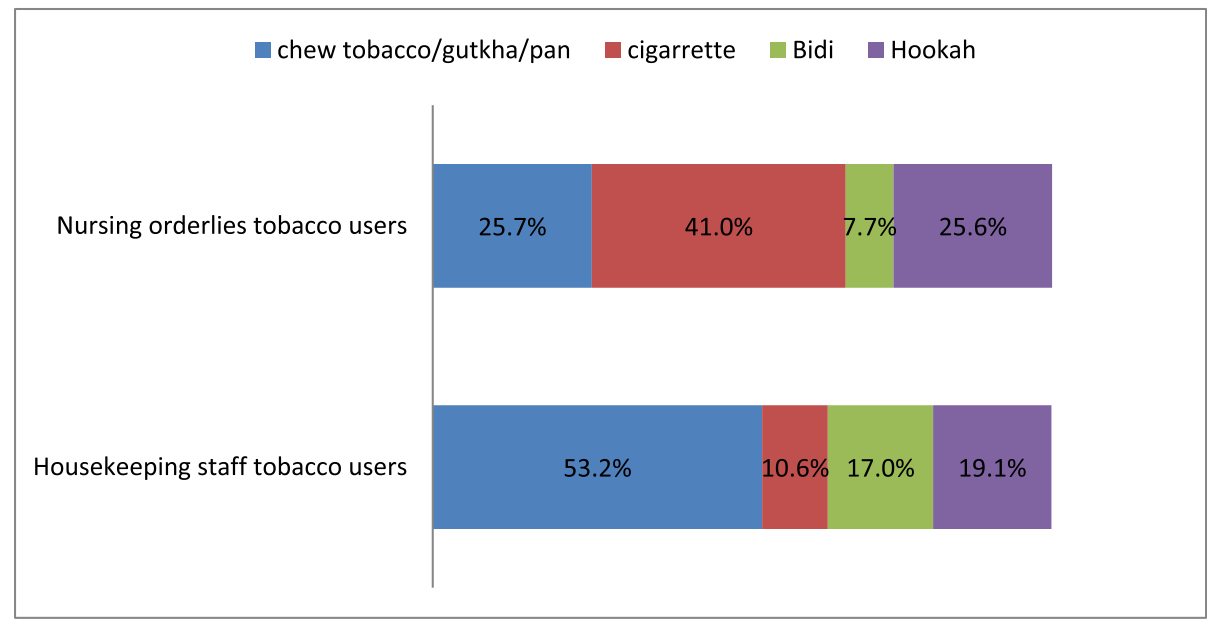

Fig. 1. Type of substance used among tobacco users. 


\subsubsection{Perceived benefits}

A commonly perceived benefit among the study participants was that all forms of smokeless tobacco prevent constipation and improve gastric motility. Those who used pan masala described it helpful in increasing saliva production so that dust and soil can be spit out. Few workers have been advised gutkha and pan masala by their family members and friends as a remedy for tooth ache. An indirect protection from the air of dissection hall and mortuary was perceived by the staff posted there.

A middle aged nursing orderly quoted that “... Pan masala prevents acidity and flatus and stool is easily passed." Another told that “... Keeping pan masala in mouth while working neutralizes all bad effects of outside air." Also reported its use to be safe as "we don't take it (khaini) inside our body we spit out so it doesn't harm our body"

\subsubsection{Lifetime exposure influences tobacco use behavior}

Few participants from a low socio economic background used smokeless form of tobacco to suppress their hunger from a young age. This was introduced to them by their family members and parents. A couple of participants imitated their father and hence started taking bidi and gutkha. A female participant was introduced to pan masala by her mother in law during pregnancy to curb her nausea and dyspepsia and which further can cut down their hospital visits. One participant retired from military services opted for job of nursing orderly was used to this habit from his service days as they had free access to cigarettes. Some participants reported that professionals including doctors smoke cigarette. Participants expressed respect for these individuals and felt that cigarette must be acceptable if they were using it.

A female quoted that "... My father had cancer and still he used to smoke, so I also started smoking the cigarette buds left by him. This helped to reduce my hunger also."

Another female said, “... When I was pregnant I used to have nausea and vomiting .... I was told by my mother in law to take pan masala so that I don't have to go to doctor for this problem. A male nursing orderly quoted that "My father used to chew tobacco, so seeing him I also started using it."The military ex-serviceman quoted "Acquired this habit from previous job in military but now in front of kids don't like to smoke." One participant said "I have seen doctors and who smoke cigarette, and heard from them that one cigarette per day does not harm."

\section{Discussion}

Previous studies on epidemiology of smoking ${ }^{9}$ and tobacco use ${ }^{10}$ in Haryana had been restricted mainly to specific groups such as adolescents ${ }^{11}$ and adults. There is paucity of literature on use of tobacco among health care staff in Haryana. Tobacco is widely used in places like hospital where we assume that the staff is aware of its ill effects. Much higher prevalence was observed among construction site and daily wage worker of Delhi $(91 \%)^{12}$ and Bhubneshwar $(88.7 \%){ }^{13}$ Smoking prevalence among industrial workers of Kuwait was $34.8 \%{ }^{14}$ and smokeless tobacco (SLT) use was $48.6 \%$ in Pakistan. ${ }^{15}$ Tobacco use among the staff (who were skilled workers) studied in this hospital setting lower as compared to unskilled workers of Delhi and Bhubneshwar.

In the current study smokeless form of tobacco was used by more than half of housekeeping staff in form of gutkha, pan masala and other chewables $(53.2 \%)$. Nursing orderly preferred smoked form i.e. cigarette (41\%). The higher proportion of SLT use among house keeping males was presumably because they have easier access to it and the form that is used is cheap. Prevalence of SLT use among adults of Haryana as per GATS-2 (2016-17) was $6.3 \%$ as compared to $19.7 \%$ prevalence of smoking. ${ }^{4}$ This brings in light the policy measure of ban on sale of smokeless form of tobacco in many states. However state of Haryana has still not imposed this ban. ${ }^{16}$ Among all the available preparations, Khaini was most popular because it is inexpensive, flavorsome and easily accessible to the housekeeping staff.

Smoking prevalence was higher among NOs as it was observed as a status symbol; their income being higher as compared to housekeeping staff. Overall use of tobacco was low among NOs as they had less breaks from duty and smoking is strictly prohibited in the hospital environment hence had to use it outside the premises. The lion's share of tobacco use in NOs was occupied by filter-tipped cigarette. Mis-belief about safety of filter-tipped cigarettes and low awareness regarding health hazards of tobacco might be responsible for this significantly higher prevalence and proportion of smoking among NOs.

Majority of the housekeeping staff had low literacy level and underestimated the potency of smokeless products and believed that as long as they do not swallow it they are protected from its harmful effects. This was similar to the findings from Pakistan. ${ }^{15}$ Perceived benefit or misconception regarding SLT being better than smoked form was quoted by many. Also the medical benefits in improving digestion have been quoted too. It has been observed that ingredients like areca nut and mixtures are considered to aid digestion and are commonly taken after meals. But the incorporation of tobacco into paan increases its addiction potential and contributes to its adverse health effects because of the more persistent use caused by the addiction. ${ }^{17}$ It is the aggressive advertising by tobacco industries which has led to increase in misconceptions and usage of these products; hiding the fact that addiction and oral cancers are still on rise. ${ }^{18}$ Several studies aimed at reducing tobacco use globally have shown that increasing taxes on tobacco products can be used as a tobacco control strategy. ${ }^{19}$ A paradox observed in current analysis is switching to smokeless form (which is apparently cheaper) as cigarettes are costly.

The themes emerged from our study echo the findings from previous qualitative research. The reason that was unique to this study population was that the nature of work of housekeeping staff leads to continuation of its use as they could easily perform their job simultaneously with tobacco consumption. Stress and loneliness leading to tobacco use has been reported in many places. ${ }^{20}$ Smoking and use of SLT as a means of socialization and relaxation were consistently discussed as the main reason for continued tobacco use. ${ }^{15,17}$ Other studies reported common reasons for smoking for all participants were to relieve boredom (58.3\%) followed by the need to feel relaxed (46.9\%), to relieve anger and frustration $(42.2 \%)$, to relieve pressure of working hard (27.2\%), to concentrate at work $(24.2 \%)$, and to mix in social situations. ${ }^{14}$

Higher prevalence of use of hookah in our study is also due to its cultural sharing among the rural north Indian men; which is seen as a symbol of companionship, solidarity and consultative process. On in depth interview it was revealed that in Haryana, hookah is deeply rooted in custom to be followed, offering in pujas; as a tradition that has to be kept alive by the next generation in family and as a offering to guest at home as a gesture. Similar argument can be given for hookah use in this region. Hence this factor becomes difficult to eradicate. This subsequently becomes a habit or addiction. People, who migrate for sake of job, tend to use the other forms like bidi and cigarette as hookah cannot be carried to different places.

Majority of the users were introduced to these preparations by their peers or family similar to those reported by a study from Bhubneshwar. ${ }^{13}$ Imitation is a major smoking behavior and has been highlighted by many in current study. People imitate those who they look up to. In current study parents, peers and even respected members of society (doctors) are the ones who have been imitated. Feeling of elation following tobacco use was also reported as a reason for initiation in a study. ${ }^{13}$ Stress and loneliness for initiating this practice were found in studies conducted by other researchers. ${ }^{21-23}$ Studies have also quoted occupational stress ${ }^{20,24}$ specifically responsible for high smoking prevalence. 
In any case, all surveys studied by us have reported the higher smoking prevalence in healthcare professionals than that of the general population, showing a substantial failure to adhere to a healthy lifestyle by the staff that is in charge to support patients in improving their behavior. Staying in close vicinity with the health care professionals does not ensure adoption of healthy lifestyles. There should be a behavior change programme through repeated education and counseling sessions. Role plays, health education and continuous reinforcing healthy behavior through various activities by involving their peers who do not consume tobacco will have a better impact.

\section{Conclusion}

It was brought to our notice that while doctors themselves are aware of adverse effects, even they could not guide the users about the proper methods to quit it. Such methods and ways should be cheap and easy to follow for general population. Proper centers should be set up where they guide people on how to quit the addiction and these modes should be marketed and publicized together with awareness programs. People have minimum concern about their necessity, implications, and violate laws at random. Legislative actions and health-propagandas like posters, banners, leaflets, etc. can change tobacco behavior of people very little, as very few of them actually know the evils of tobacco in depth. The first line of action was to help our study population locate the de addiction centers at our own institute followed by small group motivation sessions with the help of department of Psychiatry on fixed weekdays. We can in future engage these workers as both as advisers and behavioral models for the citizens in the process of smoking cessation. The physicians are widely viewed as examples by the community; hence the hospitals should represent places suitably appointed to develop a culture of health promotion. ${ }^{25}$

\section{Source of funding}

None declared.

\section{Declaration of competing interest}

None declared.

\section{References}

1. World Health Organization. The World Health Report 2002 Reducing Risks, Promoting Healthy Life Geneva 2002; 2002 Accessed from https://www.who.int/whr/2002/en/ whr02 en.pdf?ua = 1, Accessed date: 30 March 2019.

2. Patel DR. Smoking and children. [serial on the Internet]. Indian J Pediatr. 1999. [cited 2010 Aug 10]; 66, Number 6:[817-24]. Available from:. http://www. springerlink.com/content/14n26144620082p5/.

3. Warren CW, Riley L, Asma S, et al. Tobacco Use by Youth: A Surveillance Report from the Global Youth Tobacco Survey. 78. Bulletin of World Health Organization; World Health Organization; 2000:868-876. Available from: https://www.ncbi.nlm.nih. gov/pmc/articles/PMC2560802/.

4. Government of India. Ministry of Health and Family Welfare. Global Adult Tobacco Survey 2. Factsheet, Haryana 2016-17. MOHFW, New Delhi: World health organization; 2018. Available from: http://www.tiss.edu/uploads/files/06_HR.pdf, Accessed date: 16 April 2019.

5. Ferguson P, Small WP. Further study of the smoking habits of hospital nurses. Health Bull. 1985;43:13-18.

6. Olsen AD, Fugleholm AM, Rasmussen S, et al. Smoking behaviour and exposure to passive smoking among hospital employees 1992-1999. Ugeskr Laeger. 2000;162:5623-5627.

7. Nielsen PE, Falk J, Danielsen US. Smoking habits and attitudes towards the tobacco issue among health professionals in Denmark in 1996. Ugeskrift. 2000;162:4140-4144.

8. Willaing I, Ladelund S. Smoking behavior among hospital staff still influences attitudes and counseling on smoking. Nicotine Tob Res. 2004;6:369-375.

9. Khan ZA, Goel R, Mukherjee AK, et al. Prevalence and predictors of intention to quit tobacco smoking in smokers of rural area of North India (Haryana). Int J Commun Med Public Health. 2018;5(4):1617-1622.

10. Jangra A, Malik JS, Singh S, et al. Pattern of current tobacco use in a rural block of North India. Int J Commun Med Public Health. 2017;4(10):3802-3807.

11. Kapoor SK, Krishnan A, Kumar G. Prevalence of tobacco use among school and college going adolescents of Haryana. Indian J Pediatr. 1995;62(4):461-466.

12. Parashar M, Agarwalla R, Malik P, et al. Prevalence and correlates of nicotine de pendence among construction site workers: a cross sectional study in Delhi. Lung India. 2016;33(5):496-501.

13. Panigrahi A, Das BC, Panigrahi M. Tobacco use among daily wage laborers in the city of Bhubaneswar, Odisha, India. J Public Health. 2012;21(1):57-61.

14. Gaafar MA, Basiony LA. Pattern of smoking habit and quit attempts among industrial workers in Kuwait. Occup Med Health Aff. 2013;1:115.

15. Valliani A, Ahmed B, Nanji K, et al. Use of smoke-less tobacco amongst tertiary care hospital staff in Pakistan. Asian Pac J Cancer Prev APJCP. 2012;13(5):2315-2317.

16. Government of India. Ministry of health and family welfare. In: Gupta PC, Arora M, Sinha D, Asma S, Parascondola M, eds. Government of India. Smokeless Tobacco and Public Health in India Executive Summary. Regulation 2.3.4 of the Food Safety and Standards (Prohibition and Restrictions on Sales. WHO; 2012.

17. Reddy KS, Gupta PC, eds. Report on Tobacco Control in India. New Delhi: Ministry of Health and Family Welfare, Government of India; 2004 Nov:397.

18. Henningfield JE, Rose CA, Giovino GA. Brave new world of tobacco disease prevention: promoting dual tobacco product use. Am J Prevent Med. 2002;23(3):226-228.

19. Starks H, Trinidad SB. Choose your method: a comparison of phenomenology, discourse analysis, and grounded theory. Qual Health Res. 2007;17:1372-1380.

20. Choi Y, Banwell C. A qualitative study of attitudes towards smoking and antismoking measures among Korean male smokers in Australia. Glob J Health Sci. 2017;9(12):131-143.

21. Yap SF, Ho PS, Kuo HC, et al. Comparing factors affecting commencement and cessation of betel quid chewing behavior in Taiwanese adults. BMC Public Health. 2008;5:199.

22. Ali NS, Khuwaja AK, Ali T. Smokeless tobacco use among adult patients who visited family practice clinics in Karachi, Pakistan. J Oral Pathol Med. 2009;38(5):416-421.

23. Balagopal P, George N, Venugopal A, et al. Tobacco related habits among first degree relatives of patients undergoing surgery for advanced head and neck malignancies in India. Asian Pac J Cancer Prev APJCP. 2012;13:217-220.

24. McKenna H, Slater P, McCance T, et al. The role of stress, peer influence and education levels on the smoking behaviour of nurses. Int J Nurs Stud. 2003;40:359-366.

25. World Health Organization, Europe. The International Network of Health Promoting Hospitals and Health Services: Integrating Health Promotion into Hospitals and Health Services. 2007; 2007. 24pp. Available from: http://www.who-cc.dk/library/HPH \%20BROCHURE(PRINT\%20VERSION).pdf, Accessed date: 16 April 2019. 